\title{
Recidiva tardia de linfoma da zona marginal
}

\section{Late relapse of marginal zone lymphoma}

Talita M. B.S. Rocha ${ }^{1}$

Tereza C. Bortolheiro ${ }^{2}$

Eduardo Costa ${ }^{3}$

Daniela Haardt $t^{4}$

Roberto P. Paes 5

Carlos S. Chiattone ${ }^{6}$
O linfoma de zona marginal é um linfoma de baixo grau com curso clínico indolente e potencial de recidiva ${ }^{1,2}$ Apresentamos um caso de recidiva tardia após 25 anos de aparente remissão completa, levantando a possibilidade de recidiva de doença preexistente ou desenvolvimento de novo clone neoplásico. Rev. Bras. Hematol. Hemoter.

Palavras-chave: Linfoma; zona marginal; recidiva.

\section{Introdução}

No início dos anos 90 foi proposta uma nova classificação que descrevia o que atualmente é conhecido como linfoma da zona marginal, até aquele momento nomeado linfoma monocitoide. ${ }^{2}$ Atualmente, pela nova classificação da Organização Mundial da Saúde (2008) ele é subdivido nos tipos Malt, nodal e esplênico. O subtipo histológico Malt é o mais prevalente, compreendendo 5\% casos de linfoma e com alguns fatores de risco já bem determinados. O principal deles é a infecção crônica por bactérias pouco agressivas (H.Pylori, C. Psittaci, C. Jejuni, Borrelia Borgdorferi). ${ }^{3-7}$ Além das infecções crônicas, a presença de doenças autoimunes também já foi relacionada como fator de risco para este subtipo. ${ }^{2} \mathrm{O}$ subtipo nodal sistêmico é o menos prevalente, com menos de $2 \%$ dos casos de linfoma. ${ }^{8}$ Neste subtipo geralmente não há evidência de doença extranodal ou doença esplênica exclusiva, além de ter forte associação com tireoidite Hashimoto e síndrome Sjogren. ${ }^{9}$

Apesar da baixa incidência do linfoma esplênico, 2\% dos casos de neoplasias linfoides, este representa a maioria dos casos de doença linfoproliferativa crônica CD5 negativa. ${ }^{8,10}$ Sua incidência é maior nos indivíduos acima de 50 anos e não há prevalência de sexo. ${ }^{8}$ Caracteristicamente, este linfoma envolve baço e linfonodos hilares esplênicos. A infiltração da medula óssea ocorre na totalidade dos casos e caracteristicamente esta doença tem caráter indolente e evolução lenta, com bom prognóstico para a maioria dos pacientes. Este subtipo de linfoma já foi correlacionado com sorologia positiva para o vírus $\mathrm{C}$, inclusive com relatos de caso de remissão completa da doença após tratamento para erradicação do vírus. ${ }^{11}$

O tratamento está indicado quando há sintomas clínicos importantes e se baseia no uso de quimioterapia e/ou anticorpo monoclonal. ${ }^{7,12}$ Cirurgia pode ser ainda considerada em alguns casos. O prognóstico mais reservado está relacionado à presença de grandes massas, mutação do gene p53 e deleção 7q. ${ }^{1,13,14}$

\section{Relato de caso}

Apresentamos caso de paciente de 37 anos, sexo masculino, natural de São Paulo, mecânico. Deu entrada na Santa Casa de Misericórdia de São Paulo em julho de 1983 com queixa de febre e perda ponderal de $15 \mathrm{~kg}$ em um período de cinco meses. No exame físico descrito no prontuário,

\footnotetext{
${ }^{1}$ Médica Hematologista. Assistente do Serviço de Hematologia da Santa Casa de São Paulo - São Paulo, SP.

${ }_{3}^{2}$ Hematologista e Citologista. Assistente do Serviço de Hematologia da Santa Casa de São Paulo - São Paulo, SP.

${ }^{3}$ Patologista. Residente do Serviço de Patologia da Santa Casa de São Paulo - São Paulo, SP.

${ }^{4}$ Biomédica. Laboratório de Citologia da Santa Casa de São Paulo - São Paulo, SP.

${ }^{5}$ Patologista. Assistente do Serviço de Patologia da Santa Casa de São Paulo - São Paulo, SP.

${ }^{6}$ Hematologista. Chefe da Hematologia e Hemoterapia da Santa Casa de São Paulo - São Paulo, SP.
}

Santa Casa de Misericòrdia de São Paulo - São Paulo-SP

Correspondência: Talita Silveira da Rocha

Rua Marquês de Itu 579, $3^{\circ}$ andar - Vila Buarque

01221-900 - São Paulo, SP - Brasil

E-mail: tasilveira6@yahoo.com.br 
apresentava importante hepatomegalia, esplenomegalia e aumento de linfonodos em todas as cadeias avaliadas (cervical, axilar e inguinal). Os exames laboratoriais da ocasião não demonstravam anemia, leucocitose ou plaquetopenia $(\mathrm{Hb}$ 12,7mg/dL; Leuco 8.700 mil/uL com 20\% linfócitos e plaquetas de 210.000/uL). Não havia outros exames de avaliação de doença disponíveis no prontuário da época. Na ocasião, o paciente realizou USG de abdome, que mostrava tumorações hepáticas e esplênicas, aumento de gânglios abdominais, principalmente em hilo hepático, e aumento dos rins bilateralmente.

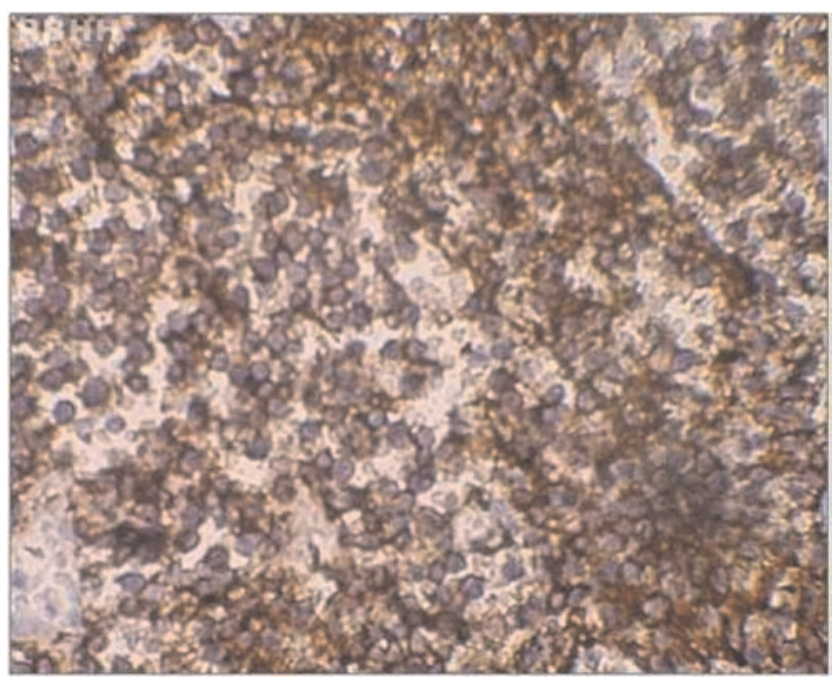

Figura 1. Biópsia de linfonodo cervical excisado em 1983. Maioria das células apresenta imunofenótipo CD20+
Foi realizada excisão de linfonodo axilar esquerdo, e o anatomopatológico e imuno-histoquímica (Figura 1) revelaram diagnóstico de linfoma linfocítico pouco diferenciado (CD20+, CD10-, CD5-, BCL2+). Na ocasião foram realizados dez ciclos de quimioterapia sistêmica com ciclofosfamida $1.400 \mathrm{mg}$; vincristina $2 \mathrm{mg}$; metotrexate $30 \mathrm{mg}$ e prednisona $100 \mathrm{mg}$.

O paciente permaneceu assintomático até junho de 2007 quando evoluiu com quadro de esplenomegalia sem sintomas sistêmicos associados. No hemograma da ocasião apresentava leucocitose com linfocitose ( $\mathrm{Hb}$ 16,4g/dl; $\mathrm{Ht}$ 49,2; leuco $23.3 \mathrm{mil} / \mathrm{uL}$ com $74 \%$ de linfócitos e plaquetas 373.000/uL). Além do hemograma, o DHL estava alterado (388u/VR:l 104-278u/L) e as dosagens das imunoglobulinas estavam normais.

A imunofenotipagem do sangue periférico foi compatível com linfoma de zona marginal esplênico (CD19+, CD20+, CD23+, CD22+, FMC7+ e CD5-, CD10-, CD79a-, CD38-, CD11b-) (Figura 2).

O paciente realizou esplenectomia por decisão da equipe médica e o resultado do anatomopatológico foi também compatível morfológica e imuno-histoquimicamente com linfoma esplênico. Após três meses de observação, o paciente foi reavaliado e, em exames laboratoriais, mantinha leucocitose com linfocitose. Na tomografia de abdome foi encontrada lesão em região da bexiga. O paciente foi encaminhado para avaliação da urologia com confirmação de diagnóstico de adenocarcinoma de bexiga. Atualmente está em tratamento de neoplasia sólida com retornos periódicos ao ambulatório.

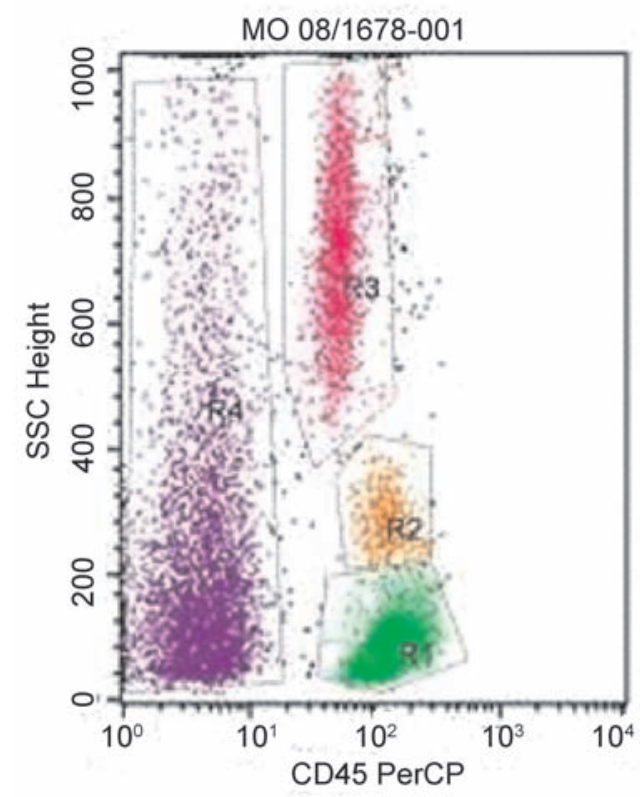

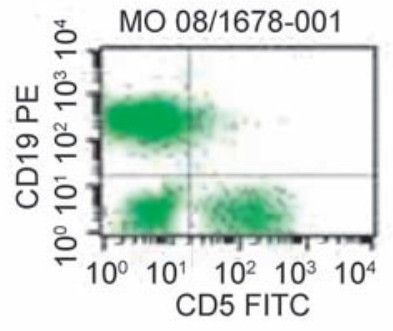

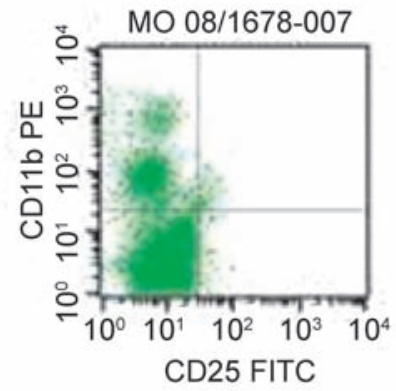

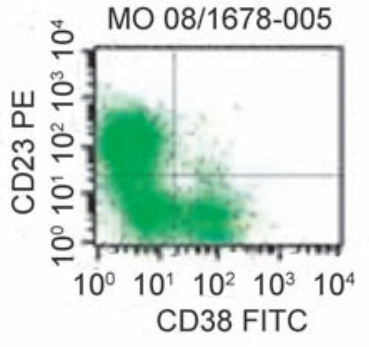

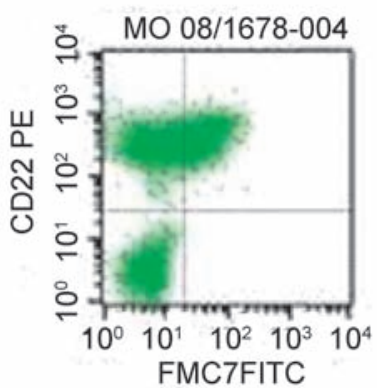

Figura 2. Imunofenotipagem de sangue periférico realizada na recidiva em 2007 compatível com o diagnóstico de linfoma esplênico da zona marginal (CD19+,CD22 positivo forte, CD5-) 


\section{Discussão}

O linfoma de zona marginal esplênico acomete principalmente indivíduos acima dos 50 anos com curso clínico indolente e caracteristicamente com esplenomegalia sem linfonodomegalias. No caso apresentado, o paciente deu entrada no serviço na quarta década de vida com quadro de linfoma sistêmico, com linfonodomegalias associadas a hepatoesplenomegalia. Nesta ocasião não possuia linfocitose no sangue periférico. Houve excelente resposta ao esquema quimioterápico proposto e o paciente permaneceu em remissão por 25 anos. Na recidiva, a apresentação da doença foi completamente distinta, com esplenomegalia sem linfonodomegalias e linfocitose no sangue periférico. A imunofenotipagem e o anatomopatológico foram compatíveis com linfoma esplênico de zona marginal (Figura 2). Neste momento foram revistas as lâminas do diagnóstico e caracterizado morfológica e imuno-histoquimicamente como linfoma de zona marginal nodal (Figura 1). Não foi encontrado nenhum caso semelhante descrito em revisão de literatura realizada no banco de dados Pubmed/Database usando-se como palavras-chaves marginal zone lymhoma com limites para língua inglesa e humanos e sem limites de data.

A raridade do caso está no fato de ser encontrada uma recidiva bastante tardia de um linfoma indolente, considerado curado na ocasião e com apresentação clínica distinta da apresentação inicial. É válido considerar que, concomitantemente, o paciente desenvolveu um carcinoma uroepitelial, e como o mesmo jamais foi tabagista e não relata casos de tumores sólidos na família, a lesão pode estar associada a toxicidade tardia do esquema quimioterápico inicialmente realizado.

\section{Abstract}

Marginal zone lymphoma is a low grade lymphoma with an indolent course and chance to relapse. We present a case of a patient who suffered relapse after 25 years of apparently complete remission of a low-grade non-Hodgkin lymphoma. Rev. Bras. Hematol. Hemoter.
5. Ferreri AJ, Ponzoni M, Guidoboni M, Resti AG, Politi LS, Cortelazzo $\mathrm{S}$, et al. Bacteria-eradicating therapy with doxycycline in ocular adnexal MALT lymphoma: a multicenter prospective trial.J Natl Cancer Inst. 2006;98(19):1375-82.

6. Lecuit M, Abachin E, Martin A, Poyart C, Pochart P, Suarez F, et al. Immunoproliferative small intestinal disease associated with Campylobacter jejuni. N Engl J Med. 2004;350(3):239-48.

7. Landgren O, Tilly H. Epidemiology, pathology and treatment of non-follicular indolent lymphomas. Leuk Lymphoma. 2008;49 Suppl 1:35-42.

8. Berger F, Felman P, Thieblemont C, Pradier T, Baseggio L, Bryon PA, et al. Non-MALT marginal zone B-cell lymphomas: a description of clinical presentation and outcome in 124 patients. Blood. 2000;95(6):1950-6.

9. Campo E, Miquel R, Krenacs L, Sorbara L, Raffeld M, Jaffe ES. Primary nodal marginal zone lymphomas of splenic and MALT type. Am J Surg Pathol. 1999;23(1):59-68.

10. Kost CB, Holden JT, Mann KP. Marginal zone B-cell lymphoma: a retrospective immunophenotypic analysis. Cytometry B Clin Cytom. 2008;74(5):282-6.

11. Szynglarewicz B, Matkowski R, Smorag Z, Forgacz J, Pudelko M, Kornafel J. Hepatitis C virus infection and locally advanced splenic marginal zone lymphoma. Pathol Oncol Res. 2007;13(4):382-4.

12. Kalpadakis C, Pangalis GA, Dimopoulou MN, Vassilakopoulos TP, Kyrtsonis MC, Korkolopoulou P, et al. Rituximab monotherapy is highly effective in splenic marginal zone lymphoma. Hematol Oncol. 2007;25(3):127-31.

13. Gruszka-Westwood AM, Hamoudi RA, Matutes E, Tuset E, Catovsky D. p53 abnormalities in splenic lymphoma with villous lymphocytes. Blood. 2001;97(11):3552-8.

14. Algara P, Mateo MS, Sanchez-Beato M, Mollejo M, Navas IC, Romero L, et al. Analysis of the $\operatorname{IgV}(\mathrm{H})$ somatic mutations in splenic marginal zone lymphoma defines a group of unmutated cases with frequent $7 \mathrm{q}$ deletion and adverse clinical course. Blood. 2002;99(4):1299-304.

Avaliação: Editor e dois revisores externos Conflito de interesse: sem conflito de interesse

Recebido: 23/04/2009

Aceito: 15/05/2009

Key words: Lymphoma; marginal zone; recidive.

\section{Referências Bibliográficas}

1. Zucca E, Bertoni F, Stathis A, Cavalli F. Marginal zone lymphomas. Hematol Oncol Clin North Am. 2008;22(5):883-901, viii.

2. Ferreri AJ, Zucca E. Marginal-zone lymphoma. Crit Rev Oncol Hematol. 2007;63(3):245-56.

3. Wotherspoon AC, Doglioni C, Diss TC, Pan L, Moschini A, de Boni $\mathrm{M}$, et al. Regression of primary low-grade B-cell gastric lymphoma of mucosa-associated lymphoid tissue type after eradication of Helicobacter pylori. Lancet. 1993;342(8871):575-7.

4. Cerroni L, Zöchling N, Pütz B, Kerl H. Infection by Borrelia burgdorferi and cutaneous B-cell lymphoma. J Cutan Pathol. 1997;24(8):457-61. 